\title{
Asian elephants exhibit post-reproductive lifespans
}

\author{
Simon N. Chapman ${ }^{1 *} \mathbb{D}$, John Jackson², Win Htut ${ }^{3}$, Virpi Lummaa ${ }^{1}$ and Mirkka Lahdenperä ${ }^{1}$
}

\begin{abstract}
Background: The existence of extended post-reproductive lifespan is an evolutionary puzzle, and its taxonomic prevalence is debated. One way of measuring post-reproductive life is with post-reproductive representation, the proportion of adult years lived by females after cessation of reproduction. Analyses of post-reproductive representation in mammals have claimed that only humans and some toothed whale species exhibit extended post-reproductive life, but there are suggestions of a post-reproductive stage for false killer whales and Asian elephants. Here, we investigate the presence of post-reproductive lifespan in Asian elephants using an extended demographic dataset collected from semi-captive timber elephants in Myanmar. Furthermore, we investigate the sensitivity of post-reproductive representation values to availability of long-term data over 50 years.

Results: We find support for the presence of an extended post-reproductive stage in Asian elephants, and that post-reproductive representation and its underlying demographic rates depend on the length of study period in a long-lived animal.

Conclusions: The extended post-reproductive lifespan is unlikely due to physiological reproductive cessation, and may instead be driven by mating preferences or condition-dependent fertility. Our results also show that it is crucial to revisit such population measures in long-lived species as more data is collected, and if the typical lifespan of the species exceeds the initial study period.
\end{abstract}

Keywords: Asian elephant, Demography, Fertility, Long-term data, Post-reproductive life, Reproductive cessation

\section{Background}

The evolution of extended post-reproductive lifespan is a long-term puzzle in evolutionary biology, where extended refers to post-reproductive lifespan that is not an artefact of individual variation in somatic and reproductive senescence rates [1]. Species with extended post-reproductive lifespans are implicitly considered to be physiologically incapable of further reproduction, and though postreproductive lifespan is often considered rare [2, 3], others claim it to be a general mammalian trait [4-6]. This controversy is due to a combination of methodological differences (reviewed in [7]), variation in definitions of what constitutes a post-reproductive period, and the fact that post-reproductive lifespan is mathematically constrained to be positive unless all females immediately die after reproduction. An age-specific decline in fertility is common among animals $[8,9]$, and iteroparous animals

\footnotetext{
* Correspondence: sinich@utu.fi

1Department of Biology, University of Turku, Turku, Finland

Full list of author information is available at the end of the article
}

are generally expected to exhibit declining fertility as a function of overall senescence [10]. However, even female primates, our nearest relatives, retain fertility close to the end of their lives $[11,12]$, resulting in a maximum postreproductive lifespan of a few years in these species [4]. Therefore, whilst some degree of post-reproductive lifespan is common across animals, post-reproductive lifespans extending well beyond regular birth intervals and covering several years or even decades are rare across the animal kingdom.

To distinguish extended post-reproductive lifespan from individual variation in senescence, measures that do not depend on any one individual are preferable to those calculated off specific individuals (e.g. expected lifespan vs maximum recorded lifespan) or individuals meeting specific criteria $[7,13]$. Individual-based measures are often correlated with overall longevity and may introduce biases through exclusion of individuals considered to have died before being able to reproduce again (see [7] for further discussion of these issues). 
Post-reproductive representation $(\mathrm{PrR})$ is a population measure that does not depend on specific individuals or limiting criteria [7], and is defined as the proportion of total adult lifespan spent in a post-reproductive state. PrR is calculated by dividing the number of years an average female newborn is expected to live postreproductively by the total number of years she is expected to live as an adult $[7,13]$. Though the applicability of $\operatorname{PrR}$ to wild populations has been questioned due to the difficulty in obtaining sufficient data [6], recent work has not only shown that PrR can be measured for wild populations, but that it remains statistically robust even in the absence of long-term data [3,14], assuming that estimated ages are accurate and a representative cross-section of a population is used. However, these conditions may not always be fulfilled in longitudinal datasets, especially if the lifespan of the animal greatly exceeds the length of the study period. Furthermore, full captivity is problematic for assessing post-reproductive life: reproductive senescence can be accelerated by breeding programmes in zoos, and exclusion of extrinsic causes of mortality can extend average lifespan [1]. Therefore it is important to assess the robustness of the dataset and to carefully select the population when estimating the existence of post-reproductive life in a species, and to use appropriate methods to overcome the acknowledged limitations of the data.

Whilst humans display a distinct and obvious end to reproduction - menopause - they are not the only species with an extended post-reproductive lifespan. It is currently thought that a 'true' post-reproductive lifespan, with a substantial proportion of females in the population being post-reproductive and living notably long thereafter, is a trait exhibited by a limited number of mammalian species (which are also physiologically incapable of further reproduction): humans, killer whales (Orcinus orca), narwhals (Monodon monoceros), beluga whales (Delphinapterus leucas), and short-finned pilot whales (Globicephala macrorhynchus) [3, 14]. All these species exhibit a $\operatorname{PrR}$ or physiological-PrR value (see [14]) between 0.15 and 0.30 i.e. $15-30 \%$ of adult female years are lived by post-reproductive individuals. False killer whales (Pseudorca crassidens) may also exhibit some degree of extended post-reproductive life $(\operatorname{PrR}=0.14$ [15], but see also [14]).

The PrR analyses of Ellis et al. [3] covered 52 mammal species with wild populations for which life tables could be constructed. However, this did not include every mammal species that could potentially exhibit extended post-reproductive life - those with similar life-history traits, including social structure, to species with extended post-reproductive life. For example, whilst African elephants (Loxodonta africana) were included in this study and were reported to have a low PrR of 0.04 (i.e. not post-reproductive), Asian elephants (Elephas maximus) were not analysed. Asian elephants have actually been shown to have a PrR shorter than that of 'true' post-reproductive species, but much longer than that of non-post-reproductive mammals $(\operatorname{PrR}=0.13$ [16]), although the significance of this has not been tested. Despite broad similarities in social structure and lifespan, African and Asian elephants are markedly different species, with mitochondrial DNA suggesting that divergence occurred 5.43-8.42 million years ago (reviewed in [17]). Ecologically, Asian elephants are distinct from African elephants, having smaller body and group sizes, and occupying the forest-grassland ecotone [18]. The fact that Asian elephants are long-lived and occur in forested habitat has made a detailed understanding of demographic variation in wild populations all but impossible (but see [19]). However, semi-captive populations in range states have the potential to provide insights into the life-history traits of this enigmatic long-lived species. Here, we first investigate the existence of extended postreproductive lifespan and the significance of $\operatorname{PrR}$ in Asian elephants, with a larger, longer-term demographic dataset than that previously used by Lahdenperä et al. [16]. Second, though Ellis et al. [3] showed that the PrR method is robust for cross-sectional and most longitudinal data, they did not have available data to show whether the methodology is also robust for longitudinally-sampled populations of long-lived species. We therefore investigate how values of $\operatorname{PrR}$ and underlying/related demographic variables change depending on the length of study, from 1960 to 2018.

To address PrR in Asian elephants, and more generally how the length of the field study affects the outcome of PrR estimates, we use detailed demographic records of 3802 females from timber camps in the Union of Myanmar, all born within the last 80 years (approximately 3-4 generations). Despite individuals being held in captivity and used in the extraction of timber, they are more frequently described as semi-captive. Crucially for the analysis of post-reproductive lifespan, mortality [20] and fertility [21] patterns in this population have been compared to wild populations, including African elephants, and distinguished from captive populations held in zoos, which have much lower survival and fertility rates. Furthermore, individuals are not culled, receive only basic veterinary care, and are not subjected to reproductive management [22]. Thus, we believe that the current study population is appropriate for the study of PrR in Asian elephants, and a valuable resource for understanding the rare occurrence of post-reproductive lifespan in mammals. More generally, a longitudinal dataset of an exceptionally long-lived mammal offers the opportunity to assess how sensitive the PrR estimation method is to truncated life histories and the instability of population structure through time (see [23]). 


\section{Methods}

\section{Study population}

Asian elephants are listed as endangered on the IUCN Red List of Threatened Species, but, unusually for an endangered species, have a large captive population of 16,000 individuals [24]. The largest captive population of elephants is in the Union of Myanmar, where $~ 2700$ state-owned elephants are currently utilised in timber extraction, which are managed by the Myanma Timber Enterprise and monitored for the current study. We formally describe this population as semi-captive for several reasons. First, elephants are used in timber extraction between June and February and work during the day, but outside daily working hours, and at night, individuals are free-roaming and forage naturally (i.e. aside from the occasional seasonal fruit, or rice if travelling longer distances, there is no food supplementation). They also roam freely in the three-month annual rest period. Second, there is no reproductive management or husbandry in the population and individuals mate freely and receive no help with calving. Third, humans do not intervene with the care of calves, who receive maternal and allomaternal care until they are trained from the age of four $[25,26]$. Finally, culling is not practised under any circumstance regardless of working ability, and elephants only have access to basic veterinary care. This care covers wound and abscess treatment, diagnosis and treatment of basic gastrointestinal diseases, vaccinations against anthrax and haemorrhagic septicaemia, and twice-yearly deworming. However, before 2000 (covering the majority of the data used here), modern veterinary care was minimal, and more than $40 \%$ of deaths in this population are directly attributable to acute or chronic illnesses or parasite infection [27].

Timber elephants are monitored by the Myanma Timber Enterprise and the current dataset has been compiled through individual logbooks and end-of-year reports (see e.g. [28] for further details). Demographic information including date of birth and origin (captiveborn, for those born to a mother already in the population, or wild-caught, for those born in the wild and captured later on), capture date (if wild-caught), date of death or date last seen, and any calves is recorded for all registered elephants. Captive-born elephants have known dates of birth, and the age of wild-caught elephants has been estimated based on a number of measures [28, 29].

We included all captive-born females born after 1940 (reaching reproductive age in the 1950s, when recordkeeping was more consistent), and any wild-caught females entering the population after 1951. As ageestimates for wild-caught individuals may have a lower accuracy after full body height is achieved [30], we included only wild-caught females captured before the age of 25. Finally, individuals with erroneous or discontinuous birth/entry and death/departure information were also removed ( $\sim 5 \%$ of elephants). The final dataset contained demographic information for 3802 females from 1940 until 2018.

\section{Constructing life tables}

We constructed life tables for females from longitudinal censored data, using $\mathrm{R}$ v3.5.1 [31]. Individuals were followed until death, unless they were last recorded as still alive in the log books, in which case they were censored at the time of last recording.

The total number of individuals at age $x$ (in years) were known, and from this we derived probabilities of survival to each age $\left(l_{x}\right)$. This was done for all elephants in the sample $(n=3802)$, but also for only captive-born elephants $(n=2568)$. We obtained $l_{x}$ from Cox proportional hazards models, which account for censoring. These were implemented with the Surv and survfit functions from the survival package [32]. For the $l_{x}$ series the ordered sequence of age-specific $l$ values - in which elephants caught from the wild were included, we created a left-censored Surv object in R, with time set as the estimated age at capture for wild-caught individuals, and as 0 years for captive-born individuals. The second time argument was then set as $1+$ age at death or $1+$ age of censoring, as the models do not accept identical entry and exit ages (e.g. elephants dying in the year of birth or capture). This one-year shift was corrected for after analysis by removing the value for age 0 (which always showed all elephants surviving).

For these two datasets, we also modified the $l_{x}$ series by decreasing the maximum age by 1 and 5 years, to see how shortening lifespan would affect PrR. This was effectively a proxy of a hypothetical wild population, under the assumption that the semi-captive elephants are living prolonged life because of their partial captivity. However, we again wish to emphasise that Asian elephants actually live shorter lives in zoos than in the working population of Myanmar [20], and therefore these $l_{x}$-altered populations may be closer to the situation for zoo Asian elephants rather than wild. For the 1 -year reductions, we replaced the last value of $l_{x}$ with 0 . For the 5 -year reduction, $l_{x}$ was modified by removing the 'extreme' ages, which involved replacing the last 5 values at the end of the $l_{x}$ series with $0 \mathrm{~s}$. Due to fairly low sample sizes at older ages, this did not remove too many observations of long-lived elephants $\left(l_{x-1}: 1\right.$ individual/1 observation; $l_{x-5}: 5$ individuals/14 observations; captive only $l_{x-1}: 4$ individual/4 observations; captive only $l_{x-5}: 15$ individuals/ 39 observations).

We then calculated fecundity at each given age $\left(m_{x}\right)$. This was determined using the birth records from individual-based log books, and provides clear evidence of female reproductive activity. To obtain $m_{x}$, we divided 
the number of offspring of either sex born in a year by $L_{x}$, the number of individual years lived between age $e_{x}$ and age $\mathrm{e}_{x+1}$ (number of individuals at age $\mathrm{e}_{x}$ - half the number of individuals dying at age $e_{x}$ ). In addition to calculating the $m_{x}$ series for the whole sample, we also calculated it for a subset containing captive-born elephants only.

Though the age at first reproduction for wild Asian elephants is currently unclear, zoo elephants have an earlier and shorter reproductive period than this semicaptive elephant population [21]. The reproduction of wild Asian elephants is probably not dissimilar to this population: first, the elephants in this population reproduce without human intervention (e.g. artificial insemination), and second, from what little demographic data is available for wild Asian elephants, no females in the wild which are thought to be over age 60 are known to have reproduced [19]. As such, we did not modify the $m_{x}$ series.

\section{Calculating post-reproductive life}

After constructing the life tables to get the $l_{x}$ and $m_{x}$ series, we calculated PrR from each series. To mathematically describe $\operatorname{PrR}$, we must first define additional demographic notation. In addition to $l_{x}$ (the proportion of individuals surviving to age $\mathrm{e}_{x}$ ), $\operatorname{PrR}$ requires calculation of $e_{x}$ (life expectancy at age $e_{x}$. Multiplication of these measures provides $T_{x}$, the total individual years lived after $x$. PrR can then be calculated from $T_{x}$ at the ages of 5 and $95 \%$ population fecundity (age $B$ and age $M$ respectively) [7]. Age $B$ and age $M$ represent the ages at the beginning of adulthood and the end of fecundity. We quantified the PrR according to the following formula:

$$
\operatorname{PrR}=\frac{T_{M}}{T_{B}}=\frac{l_{M}}{l_{B}} * \frac{e_{M}}{e_{B}}
$$

We used existing $\mathrm{R}$ code from the literature to calculate ages $B$ and $M$, and PrR for each sample (see 'S3_ Rcode' from [7]). We applied a slight modification to this code to calculate the statistical significance of the PrR value, following the method used by Ellis et al. [3], by increasing the number of simulated populations to 9999 [33]. The $p$ values for each $\operatorname{PrR}$ are calculated by dividing the number of simulated populations with a PrR exceeding the actual PrR by the number of simulations plus one (i.e. 10,000); see eq. 1 of Ruxton and Neuhäuser [33].

\section{Sensitivity of PrR to length of study}

To investigate how the PrR value and related, relevant demographic rates are affected by data availability, we re-ran the analysis on a year-by-year basis from 1960 to
2018. To do this, we only considered known individuals and birth/death/censoring events in the population in each focal year. In effect, this mimics the situation if the study ended in 1960, 1961, 1962 etc. As above, only individuals born in captivity after 1940 or captured from the wild after 1951 were included. From this, the final dataset consisted of $59 l_{x}$ and $m_{x}$ series. The code of Levitis and Lackey [7] was then used to calculate PrR, ages $B$ and $M$, and $e_{x}$ for the population on a yearly basis.

\section{Results}

The oldest elephants in our sample were 69 (captiveborn) and 76 (wild-caught), and the oldest reproductive elephants were 55 (captive-born) and 64 (wild-caught); these reproductive ages are similar to the last known age at reproduction for a population of wild Asian elephants with estimated ages [19]. The distribution of the age at last (i.e. most recent) birth in the current population (Fig. 1a) shows that there is not a clearly defined population-level cessation in reproduction, as one might expect were the elephants to undergo physiological reproductive cessation. However, Fig. 1b provides an indication of the variation between individuals in the length of post-reproductive lifespan. There are a large number of older elephants - indicated by being of age $M$ (age at $95 \%$ population fecundity; 55 years) and over - who have not reproduced for more than the mean (plus two standard deviations) inter-birth interval [16] and are thus potentially in a post-reproductive stage $(n=177 ; 65.6 \%$ of female elephants aged 55 or over).

\section{Post-reproductive representation}

The post-reproductive representation of Asian elephants was significantly larger than zero (Table 1) in all cases, ranging between 0.148 for the $l_{x-5}$ modified full population and 0.207 for the unmodified, captive-born only elephant population. That our modified populations were still similar shows the $\operatorname{PrR}$ method is, for this population at least, robust to the removal of the 'extreme' ages of the longest-lived elephants. We found a slight difference between the values for captive-born only $(\operatorname{PrR}=0.207)$ and the full population (wild-caught and captive-born; $\operatorname{PrR}=0.162$ ).

These PrR values are within the range of values for short-finned pilot whales, with the lowest value here $(\operatorname{PrR}=0.148)$ slightly higher than the value for shortfinned pilot whales with simulated population decline $(\operatorname{PrR}=0.131)$ [3]. Whilst lower than most values of species known to have an early physiological end to reproductive ability (Fig. 2), the PrR observed here is still much larger than any species without early reproductive cessation, with the nearest PrR value coming from the yellow baboon Papio cynocephalus at 0.036 [3]. 

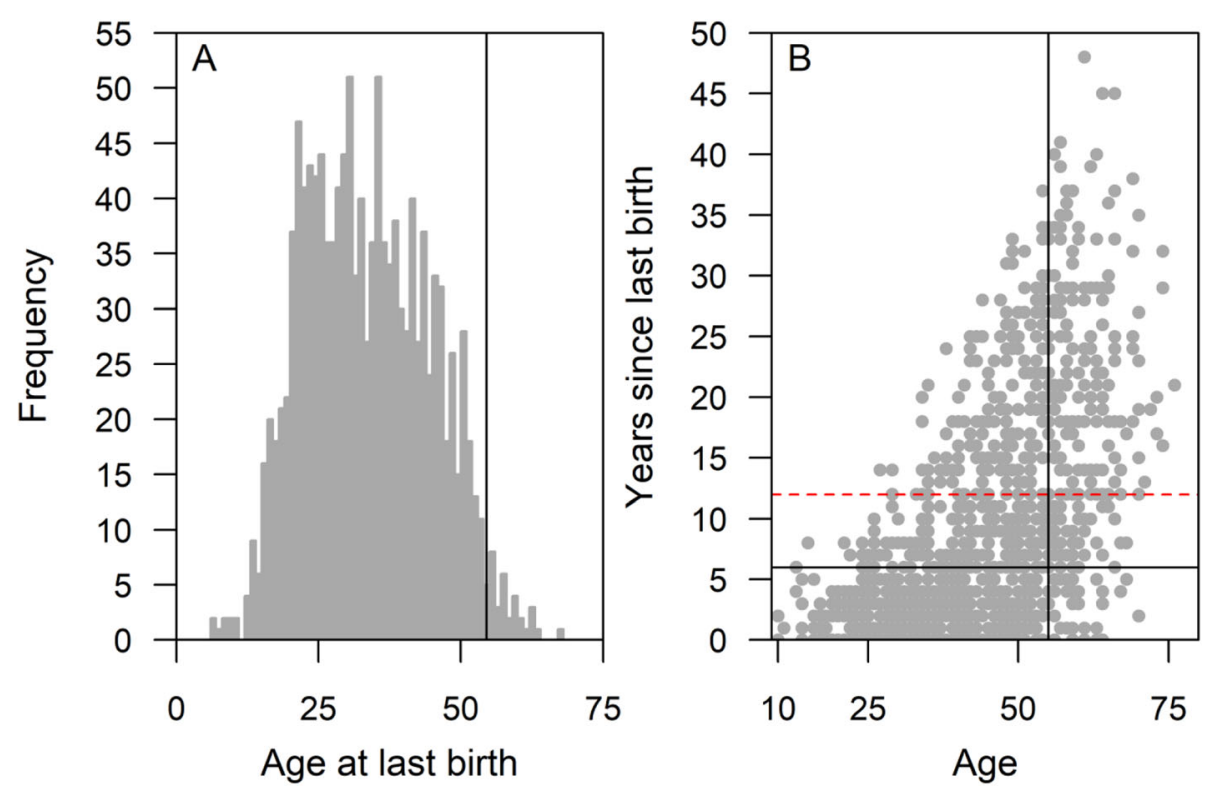

Fig. 1 Age at latest birth in the Myanmar timber elephant population. Only females reproducing at least once are shown $(n=1298)$. Vertical lines indicate age at $95 \%$ population fecundity. a histogram of frequency of ages at last birth; $\mathbf{b}$ scatterplot of years since last birth by (current/death) age of the elephants. Horizontal lines show the mean inter-birth intervals (in black) and mean plus two standard deviations (dashed red), from [16]

\section{Sensitivity of PrR to length of study}

Our second aim was to quantify how values of $\operatorname{PrR}$ and its underlying demographic variables may change depending on the length of study. There was large variation in post-reproductive representation through time (Fig. 3a; Table 2), which was initially near the high values typical of humans ( $\operatorname{PrR}>0.3$ ) [7], but declined over the study period. In the 1990s, the PrR values were very low $(<0.1)$, similar to those species described in Ellis et al. [3] as not having extended post-reproductive life. After 2000, the PrR value rose again, and appears to have begun to stabilise around 0.16 in recent years.

One cannot consider PrR alone though, as its calculation relies heavily on other demographic variables. Whilst sample size is not directly incorporated into the

Table 1 Post-reproductive representation (PrR) of Myanmar timber elephants

\begin{tabular}{llllllll}
\hline Origin & Modification & Age $B$ & Age $M$ & $e_{B}$ & $e_{M}$ & $\operatorname{PrR}$ & $p$ \\
\hline CB \& WC & Base & 17 & 55 & 25 & 5 & 0.162 & $<0.001$ \\
& $I_{x}-1$ & 17 & 55 & 25 & 5 & 0.159 & $<0.001$ \\
& $I_{x}-5$ & 17 & 55 & 25 & 5 & 0.148 & $<0.001$ \\
CB & Base & 17 & 50 & 20 & 7 & 0.207 & $<0.001$ \\
& $I_{x}-1$ & 17 & 50 & 20 & 7 & 0.205 & $<0.001$ \\
& $I_{x}-5$ & 17 & 50 & 20 & 7 & 0.192 & $<0.001$ \\
\hline
\end{tabular}

$\operatorname{PrR}$ is a measure of the proportion of adult female years lived postreproductively. CB refers to captive-born elephants, WC to wild-caught. Ages $B$ and $M$ are the ages at 5 and $95 \%$ population fecundity, respectively, whilst $e_{B}$ and $e_{M}$ are the expected female lifespan at ages $B$ and $M$ (rounded to the nearest whole number)
PrR equation, it can have a large effect on the survival and fertility series. For example, one birth will have a greater impact on the fertility rate if the sample size at that age is smaller, which may be important for slow reproducers such as elephants. The same is true for the sampling of old individuals to determine, for example, the maximum lifespan or expected survival to a given age. The number of female elephants used to calculate the demographic series rose steadily, from 998 individuals in 1960 to 3802 individuals in 2018 (Fig. 3b; Table 2). Though not used directly in the PrR equation, changes in the maximum recorded lifespan and mother age at birth can indicate whether the period of study is sufficiently capturing representative demographic rates. Both variables were low at the start of the study period, in part because of the restrictive data selection criteria we imposed, and continued to rise well into the 2000s (Fig. 3c and d; Table 2). Currently, PrR is relatively stable: the oldest recorded age has remained 76 for the past 5 years, whilst there has been no increase in the oldest age at birth since 2011 .

More importantly for the calculation of $\operatorname{PrR}$, ages $B$ and $M$ (ages at 5 and $95 \%$ population fecundity respectively) have changed considerably with the length of the longitudinal data collection (Fig. 3e and f; Table 2). Age $B$ reached 17 years in 1984, and has remained the same since then. However, the expected lifespan of females surviving to age B continued to increase up to 2015. For age $M$, there was a large increase, from 22 years in 1960 to 55 years in 2018 . Unlike with the other demographic 


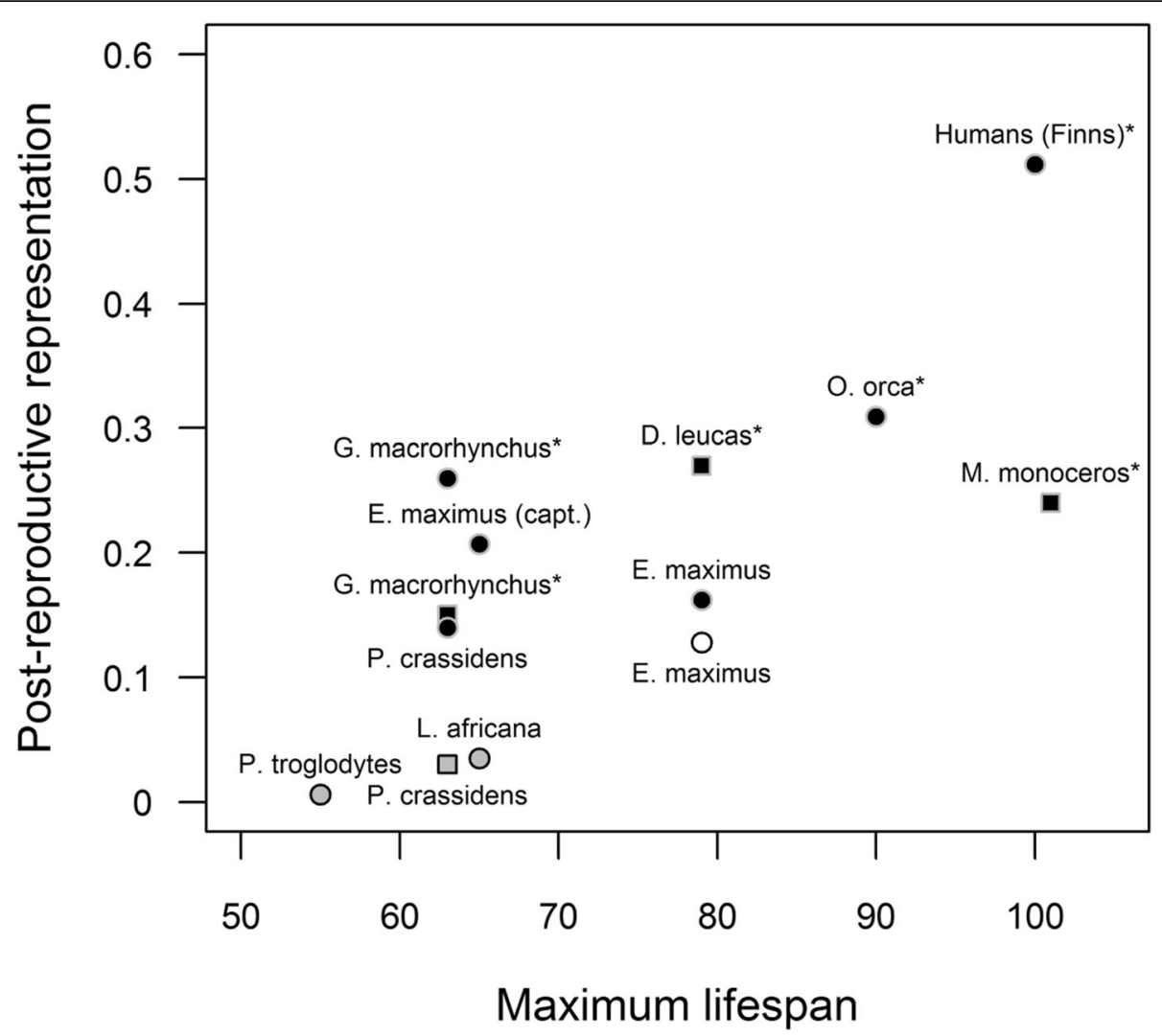

Fig. 2 Postreproductive representation values of long-lived mammals by maximum female lifespan. Species labels are above or below their point, with * indicating the species has early reproductive cessation. Colour of points indicates significance of PrR- (circle; see [7]) and physiologicallyderived PrR-values (square; see [14]): black for significant, grey for non-significant, and white for not assessed. PrR-values for humans and Asian elephants (E. maximus, white) from [16], Asian elephants (black) from this paper, killer whales (O. orca), chimpanzees (P. troglodytes), short-finned pilot whales (G. macrorhychus), and African elephants (L. Africana) from [3], false killer whales (P. crassidens) from [15], and physiological PrR-values for narwhals (M. monoceros), beluga whales (D. leucas), false killer whales, and short-finned pilot whales from [14]. Maximum female lifespan from [16] (Asian elephants and pre-industrial Finns), [34] (African elephants), [35] (killer whales), [15] (false killer whales), [36] (chimpanzees), [37] (shortfinned pilot whales), [38] (narwhals), and [39] (beluga whales)

variables, age $M$ has decreased for short periods, suggesting that it is far more susceptible to whether fertility rates are representative. It has, however, been fairly stable since 1998 (between 54 and 56 years, aside from a brief decline to 53 years in 2006 and 2007), and has remained unchanged in the last 4 years. Note that even though $e_{M}$ has not increased much (Table 2), it is relative to the value of age $M$ : elephants reaching age $M$ are still expected to live for a number of years.

\section{Discussion}

We find Asian elephants to have a statistically significant extended post-reproductive lifespan. Whilst the current population of Asian elephants is not fully wild, the elephants have better survival and later reproduction than zoo elephants $[20,21]$, and a comparable reproductive lifespan to wild elephants [19]. This could, therefore, be considered broadly representative of the species. Importantly, though the presence of a significant post-reproductive representation implicitly indicates early physiological reproductive cessation, this may not be the case. There is no clear cut age in Asian elephants after which further reproduction is impossible, unlike in e.g. humans [16] or killer whales [35]. Instead, fertility may be greatly reduced at old ages but still greater than zero [16]. As such, Asian elephants may be the first species identified as having an extended postreproductive lifespan without an early physiological cessation of reproduction.

Physiological indicators of reproduction, such as ovarian activity, can definitively show whether individuals are incapable of further reproduction. One such measure was tested for toothed whales by Ellis et al. [14], and it would be interesting for future studies to investigate this in the Asian elephant (to our knowledge, no such data have been collected). Similarly, hormonal analysis could be one future direction for 

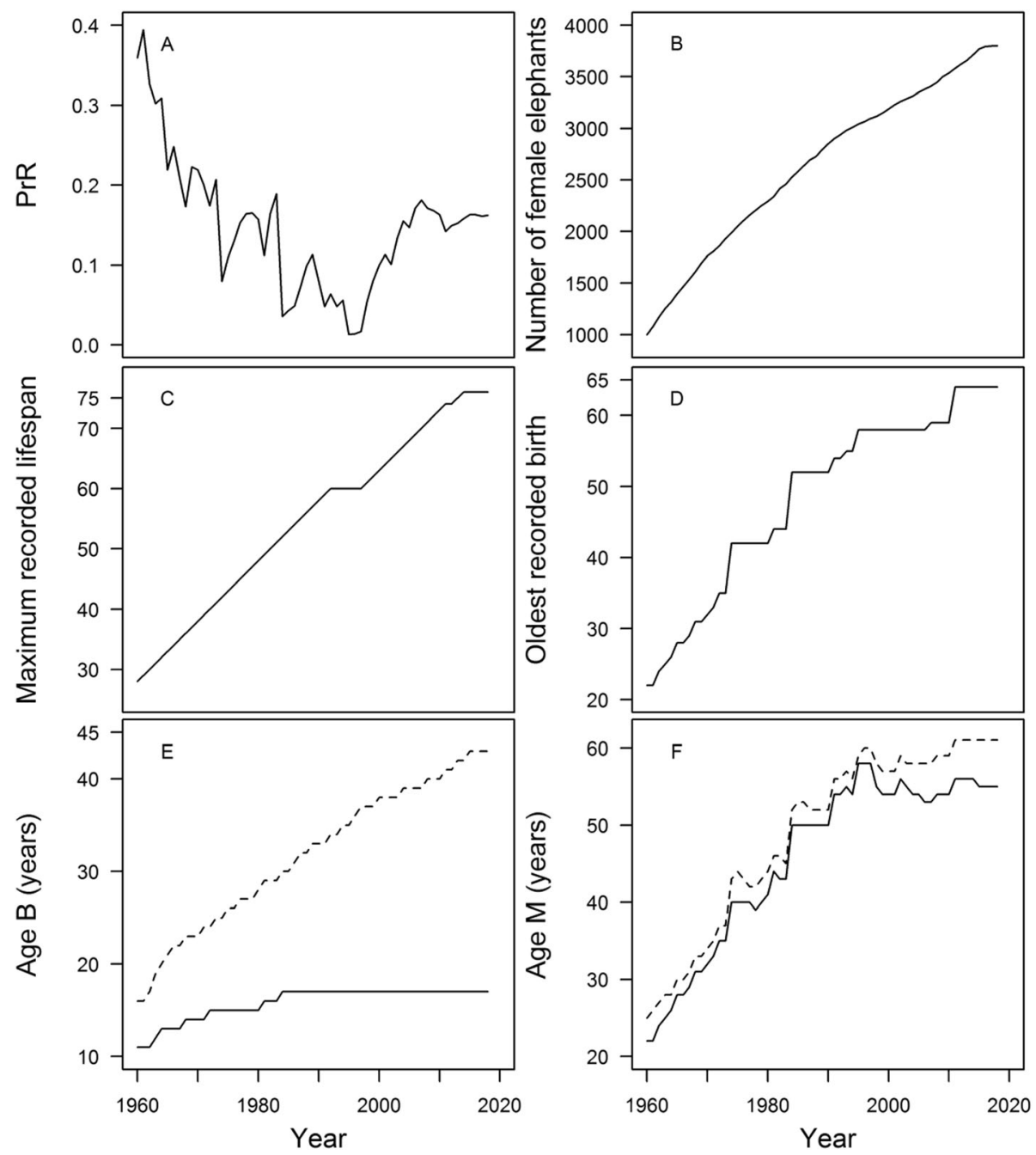

Fig. 3 Changes in PrR and demographic values from 1960 to 2018. a post-reproductive representation; $\mathbf{b}$ number of individuals in the dataset; $\mathbf{c}$ maximum recorded lifespan; d oldest age at birth; e age at $5 \%$ population fecundity (age $B$; solid line) and expected lifespan for individuals reaching these ages (age $B+e_{B}$; dashed line); $\mathbf{f}$ age at $95 \%$ population fecundity (age $M$; solid line) and expected lifespan for individuals reaching these ages (age $M+e_{M}$; dashed line). See also Table 2

establishing whether there is physiological reproductive cessation (see e.g. zoo elephants, which are known to have severe reproductive problems [40,41] and to be often acyclical/show changes in hormonal levels [42]). Though such physiological approaches to investigating post-reproductive lifespan can provide a better indication of reproductive cessation than $\operatorname{PrR}$, they can be more challenging. Measuring ovarian activity following Ellis et al. [14] would require i) opportunistic sampling of dead individuals, ii) reliable ageing of these dead individuals, which requires the validation of age estimation techniques, and iii) there to be a non-linear relationship between corpora counts and age. Hormonal analysis, meanwhile, requires longitudinal study, and can be difficult to perform on wild, living individuals. At present, we cannot assess here whether cessation of reproduction is true physiological incapability of further reproduction or whether the lack of further reproduction is due to behaviour or declining body condition.

The opportunity to reproduce may often be out of an individual's control, such as if dominant individuals suppress reproduction in subordinates [43-45]. Grandmothering may be a way for older individuals to gain fitness once the reproductive behaviours and mating preferences of others prevent further mating opportunities, or if a declining body condition at older ages affects fertility. Superseded reproductive females may switch to helping strategies, as seen in Seychelles warbler [46], carpenter bees Xylocopa pubescens [47], and social aphids Quadrartus yoshinomiyai [48, 49], without the need for early physiological reproductive cessation to evolve first 
Table 2 Changes in PrR and demographic values through time

\begin{tabular}{|c|c|c|c|c|c|c|c|c|}
\hline Cut-off year & $\mathrm{N}$ & PrR & Age $B$ & Age $M$ & $e_{B}$ & $e_{M}$ & Maximum lifespan & Oldest birth \\
\hline 1960 & 998 & 0.359 & 11 & 22 & 5 & 3 & 28 & 22 \\
\hline 1961 & 1076 & 0.394 & 11 & 22 & 5 & 4 & 29 & 22 \\
\hline 1962 & 1170 & 0.326 & 11 & 24 & 6 & 3 & 30 & 24 \\
\hline 1963 & 1253 & 0.302 & 12 & 25 & 7 & 3 & 31 & 25 \\
\hline 1964 & 1318 & 0.309 & 13 & 26 & 7 & 2 & 32 & 26 \\
\hline 1965 & 1396 & 0.219 & 13 & 28 & 8 & 2 & 33 & 28 \\
\hline 1966 & 1468 & 0.248 & 13 & 28 & 9 & 2 & 34 & 28 \\
\hline 1967 & 1535 & 0.209 & 13 & 29 & 9 & 2 & 35 & 29 \\
\hline 1968 & 1609 & 0.173 & 14 & 31 & 9 & 2 & 36 & 31 \\
\hline 1969 & 1696 & 0.223 & 14 & 31 & 9 & 2 & 37 & 31 \\
\hline 1970 & 1763 & 0.219 & 14 & 32 & 9 & 2 & 38 & 32 \\
\hline 1971 & 1807 & 0.200 & 14 & 33 & 10 & 2 & 39 & 33 \\
\hline 1972 & 1859 & 0.174 & 15 & 35 & 9 & 2 & 40 & 35 \\
\hline 1973 & 1932 & 0.207 & 15 & 35 & 10 & 2 & 41 & 35 \\
\hline 1974 & 1986 & 0.080 & 15 & 40 & 10 & 3 & 42 & 42 \\
\hline 1975 & 2051 & 0.109 & 15 & 40 & 11 & 4 & 43 & 42 \\
\hline 1976 & 2106 & 0.130 & 15 & 40 & 11 & 3 & 44 & 42 \\
\hline 1977 & 2159 & 0.153 & 15 & 40 & 12 & 2 & 45 & 42 \\
\hline 1978 & 2205 & 0.164 & 15 & 39 & 12 & 3 & 46 & 42 \\
\hline 1979 & 2251 & 0.165 & 15 & 40 & 12 & 3 & 47 & 42 \\
\hline 1980 & 2292 & 0.157 & 15 & 41 & 13 & 3 & 48 & 42 \\
\hline 1981 & 2337 & 0.112 & 16 & 44 & 13 & 2 & 49 & 44 \\
\hline 1982 & 2415 & 0.164 & 16 & 43 & 13 & 3 & 50 & 44 \\
\hline 1983 & 2459 & 0.189 & 16 & 43 & 13 & 2 & 51 & 44 \\
\hline 1984 & 2528 & 0.036 & 17 & 50 & 13 & 2 & 52 & 52 \\
\hline 1985 & 2580 & 0.043 & 17 & 50 & 13 & 3 & 53 & 52 \\
\hline 1986 & 2639 & 0.049 & 17 & 50 & 14 & 3 & 54 & 52 \\
\hline 1987 & 2697 & 0.073 & 17 & 50 & 15 & 2 & 55 & 52 \\
\hline 1988 & 2727 & 0.099 & 17 & 50 & 15 & 2 & 56 & 52 \\
\hline 1989 & 2793 & 0.113 & 17 & 50 & 16 & 2 & 57 & 52 \\
\hline 1990 & 2851 & 0.080 & 17 & 50 & 16 & 2 & 58 & 52 \\
\hline 1991 & 2900 & 0.048 & 17 & 54 & 16 & 2 & 59 & 54 \\
\hline 1992 & 2940 & 0.064 & 17 & 54 & 17 & 2 & 60 & 54 \\
\hline 1993 & 2982 & 0.048 & 17 & 55 & 17 & 2 & 60 & 55 \\
\hline 1994 & 3012 & 0.056 & 17 & 54 & 18 & 2 & 60 & 55 \\
\hline 1995 & 3042 & 0.013 & 17 & 58 & 18 & 1 & 60 & 58 \\
\hline 1996 & 3066 & 0.014 & 17 & 58 & 19 & 2 & 60 & 58 \\
\hline 1997 & 3097 & 0.017 & 17 & 58 & 20 & 2 & 60 & 58 \\
\hline 1998 & 3118 & 0.054 & 17 & 55 & 20 & 3 & 61 & 58 \\
\hline 1999 & 3148 & 0.080 & 17 & 54 & 20 & 3 & 62 & 58 \\
\hline 2000 & 3190 & 0.100 & 17 & 54 & 21 & 3 & 63 & 58 \\
\hline 2001 & 3230 & 0.113 & 17 & 54 & 21 & 3 & 64 & 58 \\
\hline 2002 & 3262 & 0.101 & 17 & 56 & 21 & 3 & 65 & 58 \\
\hline 2003 & 3287 & 0.134 & 17 & 55 & 21 & 3 & 66 & 58 \\
\hline
\end{tabular}


Table 2 Changes in PrR and demographic values through time (Continued)

\begin{tabular}{lllllllll}
\hline Cut-off year & $N$ & PrR & Age $B$ & Age $M$ & $e_{B}$ & $e_{M}$ & Maximum lifespan & Oldest birth \\
\hline 2004 & 3315 & 0.155 & 17 & 54 & 22 & 4 & 67 & 58 \\
2005 & 3352 & 0.147 & 17 & 54 & 22 & 4 & 68 & 58 \\
2006 & 3379 & 0.171 & 17 & 53 & 22 & 5 & 69 & 58 \\
2007 & 3408 & 0.181 & 17 & 53 & 22 & 5 & 70 & 59 \\
2008 & 3446 & 0.171 & 17 & 54 & 23 & 5 & 71 & 59 \\
2009 & 3502 & 0.168 & 17 & 54 & 23 & 5 & 72 & 59 \\
2010 & 3536 & 0.163 & 17 & 54 & 23 & 5 & 73 & 64 \\
2011 & 3582 & 0.142 & 17 & 56 & 24 & 5 & 74 & 64 \\
2012 & 3623 & 0.149 & 17 & 56 & 24 & 5 & 74 & 64 \\
2013 & 3661 & 0.152 & 17 & 56 & 25 & 5 & 75 & 64 \\
2014 & 3715 & 0.158 & 17 & 56 & 25 & 5 & 76 & 64 \\
2015 & 3769 & 0.163 & 17 & 55 & 26 & 6 & 76 & 64 \\
2016 & 3793 & 0.163 & 17 & 55 & 26 & 6 & 76 & 64 \\
2018 & 3799 & 0.161 & 17 & 55 & 26 & 6 & 76 & 64
\end{tabular}

Ages $B$ and $M$ are the ages at 5 and $95 \%$ population fecundity, respectively, whilst $e_{B}$ and $e_{M}$ are the expected female lifespan at ages $B$ and $M$ (rounded to the nearest whole number)

(though Q. yoshinomiyai may actually have an early physiological end to reproduction [48]). However, as there is no evidence of dominance status being lost with age in the Asian elephant, this may not apply for this species. Regardless, post-reproductive lifespan is not inherently limited to species with early physiological reproductive cessation, but would still require some consistency in behaviour or somatic decline at the population level that decreases reproductive opportunities for females at older ages. Whilst we are currently unable to demonstrate 'social menopause', the findings here do not eliminate it as a possibility. Although the use of inter-birth intervals is problematic [13], our results show that older female elephants are generally not reproducing, and have not done so for many years.

Our results also highlight an important issue in assessing PrR for long-lived species: the need for sufficiently long follow-up in longitudinal datasets. Here, we find a $\operatorname{PrR}$ of 0.162 , higher than the value calculated in a previous assessment with the same population (0.128) [16], indicating that values can change for species as longterm studies continue. Indeed, our analyses show that the point at which a longitudinally-studied species is assessed is crucial. Our selection criteria for elephants in early years led to elevated values for PrR, creating the striking contrast with the low values of the 1990s. A population with a more representative age structure at the beginning would still show similar extremes, though not necessarily following the same pattern, until agespecific fertility rates could be reliably calculated.

It is therefore important for future studies to consider when a species is assessed if they are calculating post- reproductive lifespan for long-lived species in which the study period is shorter than the typical adult lifespan. This issue can be alleviated by highly accurate age estimation for individuals of all ages, though there can be difficulties with verifying such estimation methods. For example, size cannot be used for accurate age estimation if growth is determinate and individuals have reached the asymptote of growth [30, 50]. Furthermore, as we find a difference between captiveborn only and the captive-born and wild-caught samples, it is clear that PrR values are sensitive to the population of study, and to its present population dynamics [23]. For example, humans are widely regarded as menopausal, but PrR values can vary greatly between populations [13]. Whilst we do not dispute the post-reproductive status of those toothed whale species shown to be post-reproductive $[3,14]$, we wish to highlight that it is possible that other long-lived species have extended post-reproductive lifespan but currently lack sufficient data for statistical assessment.

\section{Conclusions}

Due to the rarity of early reproductive cessation, we still do not know whether its evolution requires a specific driver or drivers. It may be that the prolonged post-reproductive lifespans of Asian elephants are currently driven by behaviour or body condition, rather than reproductive physiology, and may therefore be in an evolutionary transition; an extended post-reproductive life may be a prerequisite of an early end to reproductive capabilities. To properly tackle the puzzle provided by the evolution of early reproductive cessation and post-reproductive lifespan, we first need to know the taxonomic prevalence of these traits, underscoring the importance of long-term studies on known-age individuals. 


\section{Supplementary information}

Supplementary information accompanies this paper at https://doi.org/10. 1186/s12862-019-1513-1.

Additional file 1. Dataset containing the $I_{x}$ and $m_{x}$ series of the population.

Additional file 2. Dataset containing the changing $I_{x}$ and $m_{x}$ series of the population (1960-2018).

\section{Abbreviations}

PrR: Post-reproductive representation

\section{Acknowledgements}

We thank the Ministry of Natural Resources and Environmental Conservation and the Government of the Union of Myanmar for giving permission to work with Myanma Timber Enterprise. We thank Myanma Timber Enterprise for granting access to their records and elephants, and Thuzar Thwin, Mumu Thein, Khin Than Win, Khyne Mar, and numerous MTE officers for data collection and compilation.

\section{Authors' contributions}

SNC and ML conceived the project, with contribution from $V L$ and JJ. $V L, J J$, $\mathrm{WH}$, and $\mathrm{ML}$ were involved with acquisition of data. SNC conducted statistical analysis, and all authors were involved in interpretation. SNC and JJ wrote the first draft. All authors provided significant input on subsequent drafts. All authors read and approved the final manuscript.

\section{Funding}

This study was funded by the Academy of Finland (grant 26080465; VL, SNC, $\mathrm{ML}$ ), the Natural Environment Research Council $(\mathrm{JJ})$, the European Research Council (VL), and the Kone Foundation (ML). The funding bodies had no role in the study design, data collection, analysis, interpretation, or writing of the manuscript.

\section{Availability of data and materials}

The $\mathrm{R}$ code used in this study is from the published literature, and slightly modified as outlined in the Methods. The $I_{x}$ and $m_{x}$ series for the elephants can be found as Supporting Information files (Additional files 1 and 2).

\section{Ethics approval and consent to participate}

Not applicable.

\section{Consent for publication}

Not applicable.

\section{Competing interests}

The authors declare that they have no competing interests.

\section{Author details}

${ }^{1}$ Department of Biology, University of Turku, Turku, Finland. '2Department of Animal and Plant Sciences, University of Sheffield, Sheffield, UK. ${ }^{3}$ Myanma Timber Enterprise, Ministry of Natural Resources and Environment Conservation, Yangon, Myanmar.

Received: 24 June 2019 Accepted: 16 September 2019

Published online: 21 October 2019

\section{References}

1. Croft DP, Brent LJN, Franks DW, Cant MA. The evolution of prolonged life after reproduction. Trends Ecol Evol. 2015;30:407-16.

2. Alberts SC, Altmann J, Brockman DK, Cords M, Fedigan LM, Pusey A, et al. Reproductive aging patterns in primates reveal that humans are distinct. Proc Natl Acad Sci. 2013;110:13440-5.

3. Ellis S, Franks DW, Nattrass S, Cant MA, Bradley DL, Giles D, et al. Postreproductive lifespans are rare in mammals. Ecol Evol. 2018;8: 2482-94.

4. Cohen AA. Female post-reproductive lifespan: a general mammalian trait. Biol Rev. 2004;79:733-50.

5. Finch CE, Holmes DJ. Ovarian aging in developmental and evolutionary contexts. Ann N Y Acad Sci. 2010;1204:82-94.
6. Nichols HJ, Zecherle L, Arbuckle K. Patterns of philopatry and longevity contribute to the evolution of post-reproductive lifespan in mammals. Biol Lett. 2016;12:20150992.

7. Levitis DA, Lackey LB. A measure for describing and comparing postreproductive life span as a population trait. Methods Ecol Evol. 2011;2: 446-53.

8. Packer C, Tatar M, Collins A. Reproductive cessation in female mammals. Nature. 1998;392:807-11.

9. Ricklefs RE, Scheuerlein A, Cohen A. Age-related patterns of fertility in captive populations of birds and mammals. Exp Gerontol. 2003;38:741-5.

10. Hamilton WD. The moulding of senescence by natural selection. J Theor Biol. 1966;12:12-45.

11. Caro TM, Sellen DW, Parish A, Frank R, Brown DM, Voland E, Borgerhoff Mulder M. Termination of reproduction in nonhuman and human female primates. Int J Primatol. 1995:16:205-20.

12. Pavelka MSM, Fedigan LM. Menopause: a comparative life history perspective. Am J Phys Anthropol. 1991;34:13-38.

13. Levitis DA, Burger O, Lackey LB. The human post-fertile lifespan in comparative evolutionary context. Evol Anthropol. 2013;22:66-79.

14. Ellis S, Franks DW, Nattrass S, Currie TE, Cant MA, Giles D, et al. Analyses of ovarian activity reveal repeated evolution of post-reproductive lifespans in toothed whales. Sci Rep. 2018;8:12833.

15. Photopoulou T, Ferreira IM, Best PB, Kasuya T, Marsh H. Evidence for a postreproductive phase in female false killer whales Pseudorca crassidens. Front Zool. 2017;14:1-14

16. Lahdenperä M, Mar KU, Lummaa V. Reproductive cessation and postreproductive lifespan in Asian elephants and pre-industrial humans. Front Zool. 2014:11:54

17. Roca AL, Ishida Y, Brandt AL, Benjamin NR, Zhao K, Georgiadis NJ. Elephant natural history: a genomic perspective. Annu Rev Anim Biosci. 2015:3:139-67.

18. Sukumar R. The living elephants: evolutionary ecology, behaviour, and conservation. Oxford: Oxford University Press; 2003.

19. de Silva S, Webber CE, Weerathunga US, Pushpakumara TV, Weerakoon DK, Wittemyer G. Demographic variables for wild Asian elephants using longitudinal observations. PLoS One. 2013;8:e82788.

20. Clubb R, Rowcliffe M, Lee P, Mar KU, Moss C, Mason GJ. Compromised survivorship in zoo elephants. Science. 2008;322:1649.

21. Clubb R, Rowcliffe M, Lee P, Mar KU, Moss C, Mason GJ. Fecundity and population viability in female zoo elephants: problems and possible solutions. Anim Welf. 2009:18:237-47.

22. Mar KU (2007) The demography and life history strategies of timber elephants in Myanmar. PhD Thesis.

23. Jackson J, Childs DZ, Mar KU, Htut W, Lummaa V. Long-term trends in wildcapture and population dynamics point to an uncertain future for captive elephants. Proc R Soc B. 2019;286:20182810.

24. Choudhury A, Choudhury DKL, Desai A, Duckworth JW, Easa PS, Johnsingh ATJ, et al. (2008) Elephas maximus. Available at: www.iucnredlist.org.

25. Lahdenperä M, Mar KU, Lummaa V. Nearby grandmother enhances calf survival and reproduction in Asian elephants. Sci Rep. 2016:6:27213.

26. Lynch EC, Lummaa V, Htut W, Lahdenperä M. Evolutionary significance of maternal kinship in a long-lived mammal. Philos Trans R Soc B. 2019;374: 20180067

27. Lynsdale CL, Mumby HS, Hayward AD, Mar KU, Lummaa V. Parasiteassociated mortality in a long-lived mammal: variation with host age, sex, and reproduction. Ecol Evol. 2017:7:10904-15.

28. Lahdenperä M, Mar KU, Courtiol A, Lummaa V. Differences in age-specific mortality between wild-caught and captive-born Asian elephants. Nat Comms. 2018:9:3023.

29. Arivazhagan C, Sukumar R. Constructing age structures of Asian elephant populations: a comparison of two field methods of age estimation. Gajah. 2008:29:11-6.

30. Mumby HS, Chapman SN, Crawley JAH, Mar KU, Htut W, Thura Soe A, et al. Distinguishing between determinate and indeterminate growth in a longlived mammal. BMC Evol Biol. 2015:15:214

31. Core Team R. R: a language and environment for statistical computing. Vienna: R Foundation for Statistical Computing; 2018. Available at: http:// www.r-project.org

32. Therneau T (2015) A package for survival analysis in S. Available at: https:// cran.r-project.org/package=survival.

33. Ruxton GD, Neuhäuser M. Improving the reporting of P-values generated by randomization methods. Methods Ecol Evol. 2013;4:1033-6. 
34. Moss CJ. The demography of an African elephant (Loxodonta africana) population in Amboseli, Kenya. J Zool. 2001;255:145-56.

35. Ward EJ, Parsons K, Holmes EE, Balcomb KC III, Ford JKB. The role of menopause and reproductive senescence in a long-lived social mammal. Front Zool. 2009;6:4.

36. Hill K, Boesch C, Goodall J, Pusey A, Williams J, Wrangham R. Mortality rates among wild chimpanzees. J Hum Evol. 2001;40:437-50.

37. Kasuya T, Marsh H. Life history and reproductive biology of the short-finned pilot whale, Globicephala macrorhynchus, off the Pacific coast of Japan. Rep Int Whal Comm. 1984;6:259-310.

38. Garde E, Hansen SH, Ditlevsen S, Tvermosegaard KB, Hansen J, Harding KC, Heide-Jørgensen MP. Life history parameters of narwhals (Monodon monoceros) from Greenland. J Mammal. 2015;96:866-79.

39. Stewart REA, Campana SE, Jones CM, Stewart BE. Bomb radiocarbon dating calibrates beluga (Delphinapterus leucas) age estimates. Can J Zool. 2006;84: 1840-52.

40. Clubb R, Mason G. A review of the welfare of zoo elephants in Europe; 2002.

41. Hermes R, Saragusty J, Schaftenaar W, Göritz F, Schmitt DL, Hildebrant TB. Obstetrics in elephants. Theriogenology. 2008;70:131-44.

42. Brown JL. Reproductive endocrine monitoring of elephants: an essential tool for assisting captive management. Zoo Biol. 2000;19:347-67.

43. Hackländer K, Möstl E, Arnold W. Reproductive suppression in female Alpine marmots, Marmota marmota. Anim Behav. 2003;65:1-8.

44. Young AJ, Carlson AA, Monfort SL, Russell AF, Bennett NC, Clutton-Brock T. Stress and the suppression of subordinate reproduction in cooperatively breeding meerkats. Proc Natl Acad Sci. 2006;103:12005-10.

45. Beehner JC, Lu A. Reproductive suppression in female primates: a review. Evol Anthropol. 2013;22:226-38.

46. Richardson DS, Burke T, Komdeur J. Grandparent helpers: the adaptive significance of older, postdominant helpers in the Seychelles warbler. Evolution. 2007:61:2790-800.

47. Hogendoorn K, Leys R. The superseded female's dilemma: ultimate and proximate factors that influence guarding behaviour of the carpenter bee Xylocopa pubescens. Behav Ecol. 1993;33:371-81.

48. Uematsu K, Kutsukake M, Fukatsu T, Shimada M, Shibao H. Altruistic colony defense by menopausal female insects. Curr Biol. 2010;20:1182-6.

49. Uematsu K, Shimada M, Shibao H. Juveniles and the elderly defend, the middle-aged escape: division of labour in a social aphid. Biol Lett. 2013;9:2-5

50. Chapman SN, Mumby HS, Crawley JAH, Mar KU, Htut W, Thura Soe A, et al. How big is it really? Assessing the efficacy of indirect estimates of body size in Asian elephants. PLoS One. 2016;11:e0150533.

\section{Publisher's Note}

Springer Nature remains neutral with regard to jurisdictional claims in published maps and institutional affiliations.

Ready to submit your research? Choose BMC and benefit from:

- fast, convenient online submission

- thorough peer review by experienced researchers in your field

- rapid publication on acceptance

- support for research data, including large and complex data types

- gold Open Access which fosters wider collaboration and increased citations

- maximum visibility for your research: over $100 \mathrm{M}$ website views per year

At $\mathrm{BMC}$, research is always in progress.

Learn more biomedcentral.com/submissions 